\section{The Champagne Artifact in Negative Staining TEM}

John J. Bozzola, Southern Illinois University

Negative staining is a simple yet extremely useful procedure for examining nanometer-sized specimens such as intact microorganisnits (viruses and some bacteriaj), subcellular components, and even nonbiological particulates. It is a well established procodure, with extensive literature in many disciplines (Hayat and Miller, 1990). Although numerous variations exist, the basic procedure inwolves placing the specimen and stain onto a grid containing a substrate - usually plastic with or without a carbon backing. The stains consist of salts of heawy metals such as tungsten, uranium, or molybdenum which surround and often penetrate the specimen. After drying into an amorphous, glass-like background, the stains provide contrast based upon differential thickness. Areas containing thicker deposits of stain will appear darker. For example, viruses will usually show a dark halo surrounding the particless since the stain is held tightly against the particles due to surface tension forces.

Negative staining is a misleading term since it implies negalive contrast: macromolecules should appear light against a darkly stained background. In fact, most negative stains will show both positive and negative staining since the stain may react with macromolecules (uranyl acatate and DNÁ, for exemple) as well as surround the specimen.

A curious phenomenon, which some researchers have dubbed 'champagning' (I. L. Shechmeister, personal communication), may be abserved under certain conditions. In these cases, instead of a smooth, amorphous stain, there appear scattered throughout the stain numerous holes which some imaginative scientists claim resemble the bubbles seen in champagne. Unlike the latter, however, the bubbles seen in negative stains do not elicit a euphoric reaction since they often obscure the fine details of the specimen and may be mistaken for actual macromolecules, It is impotant to be able to recognize these artifacts and to minimize or eliminate the cocourrence of this phenomenon.

Figure 1 shows a single herpes virus obtained from the urine of an in- fant congenitally infected with cytornegalowirus. The urine was ultracentrifuged to concentrate the virus and the sediment suspended in 50 microliters of $2 \%$ ivit vol) potassium phosphotungstate. Various degrees of champagning are evident, ranging from large, clear circular areas cluslered to one side of the virus as well as tiny, translucent, particle-like situctures scattered throughout the entire background. Although the microscopist would have no problem recognizing the viral particles, the busy background would interfere with any attempts to react the virus with specific antibody.

Figure 2 shows three, membrane-bound, parainfluenza viruses stained with potassium phosphotungstate. In this instance, champagning occurs as anly the tiny, particle-like structures scattered throughout the background.

Figure 3 shows a single membrane-bound Sendai virus with minimal champagning arlifact. In this instance (as in Figure 2) the halo surrounding the virus particle contains actual surface projections in the membrane of the virus, The two, large, circular bodies are portions of membrane probably derived from disrupted host cells.

In my own experience, champagning may oocur under a variety of conditions. Although I have listed the conditions, please be aware that these are, by no means, all-indusive and other conditions may possibly induce the arlifact. $A$ summary of these conditions follows:

1. Improper spreading of the negative stain aver the surface of the substrate. This may be caused by the hydrophobic nature of the carbon coating. Use a high voltage, AC glow-discharge unit to treat the grids just before depositing the specimen and stain onto the grid. Include a wetting agent such a bovine serum altumin ( $1 \%$ volwol) in the negative stain solution.

2. Inadequate drying of the specimen. If water is trapped in the preparation, it will boil under the beam and high vacuum the TEM. Make sure that the specimen is totally dry before insertion into the microscope. Dry the specimen in a 45-60 degree oven for at least 20 minutes prior to examination. In addition, use the minimum amount of irradiation of the specimen by the electron beam (small spot size in $\mathrm{C2}$ ). If more beam current is needed, critically observe the specimen as the current is increased to detect the development of the artifact.

3. Inclusion of volatile substances in the specimen. Sucrose, for example, may

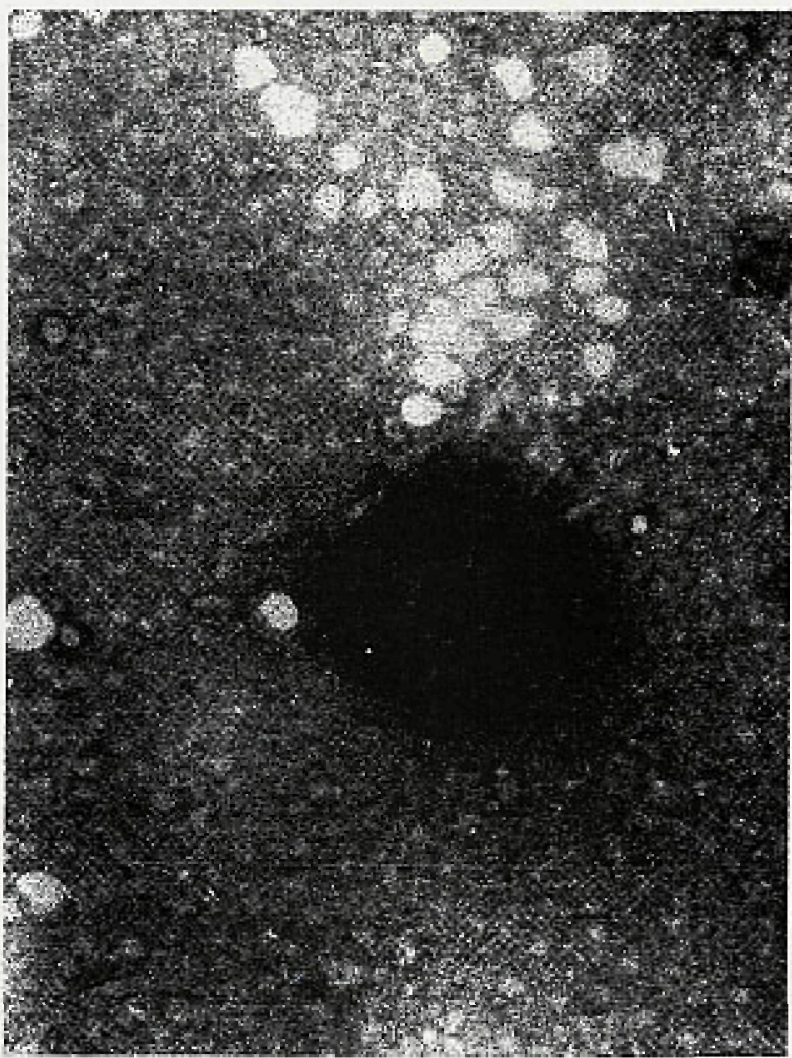

Figure 1 - Herpes Virus

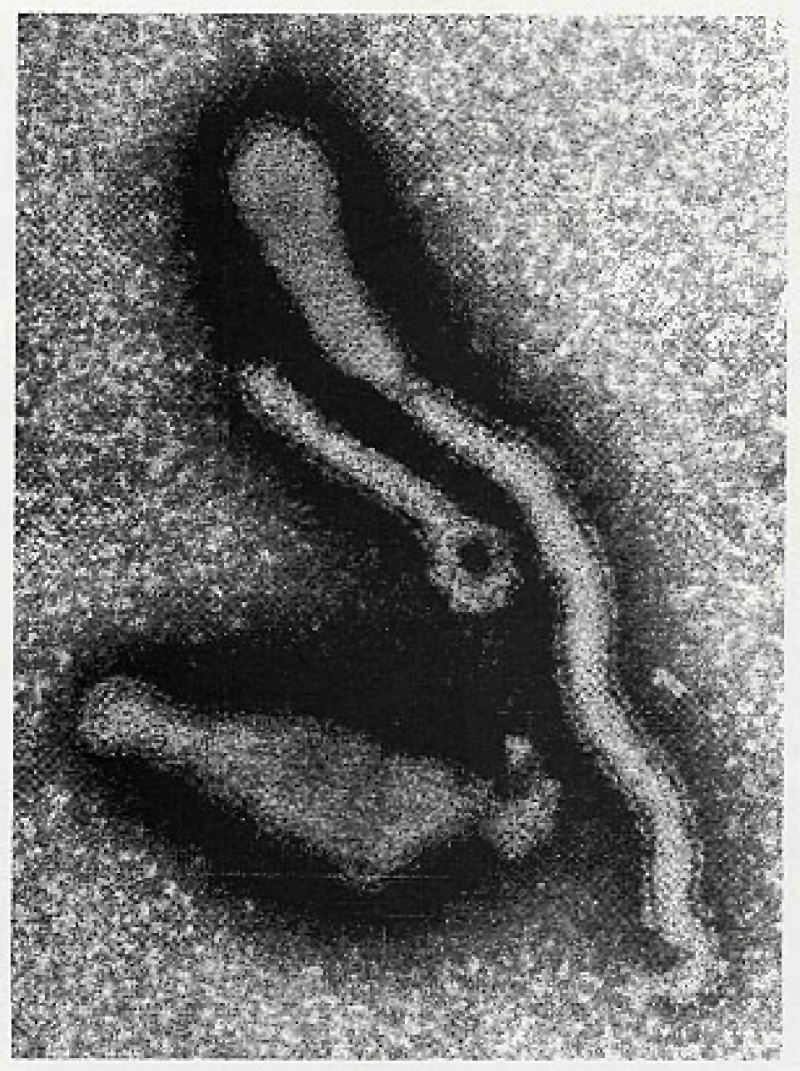

Figure 2 - Paraintluenza Virus 
be present in the sample and will quickly melt and boil in the electron beam. Whenever possible, remove the sucrose by dialysis or centrifugation. Some salts may behave in a similar manner

4. Clumped or overly concentrated preparations. Such dense deposits of organic materials tend to sequester moisture and trap sugars and salts which boil or even explode under the beam. Dilute such preparations and disperse them by gentle pipelting or storage overnight in a buffered solution.

Recognizing this artifact is difficult for beginners and sometimes even experienced microscopists have mistaken the artifact for real structure. Two good ways to detect the artifact would be to: (a) use a variety of negative stains and staining conditions on the same specimen and (b) critically observe the stain background immediately when the beam irradiates it since the artifact can be observed to form in the microscope. If you are still unable to determine if the structures are real, then avoid the use of stains and try low angle shadowing of the specimen with platinum - as is used to cantrast nucleic acids (Trendelenturg and Puvion-Dutilleul; 1987, Willison and Rowe, 1980). You could contact other microscopists experienced with negative staining technique and ask them to perform a stain on your specimen. If they succeed with your specimen, then it would be worthwile spending some time in their laboratory learning what you are doing wrong. Once you have determined the cause of your problem, a champagne toast would be in order.

References:

Hayat, MA, and S. E. Miller. 1990. Negalive Staining. MoGraw-Hill Publishing Co., New York.

Trendelenburg, M.F. and F. Puvion-Dutilleul. 1987. Visualizing active genes. IN: Electron Microscopy in Molecular Biology, A Practical Approach. J. Sommerville and U. Scheer, eds IRL Press, Oxford, England.

Willison, J.H.M, and Rowe, A.J. 1980. Practical Methods in Electron Microscopy. Volume 8: Replica, Shadowing and Freeze-Etching Techicues. (Ed. A.M. Glauerth, Elsevier'North-Holland Publishing $\mathrm{Co}$. (The Netherlands)

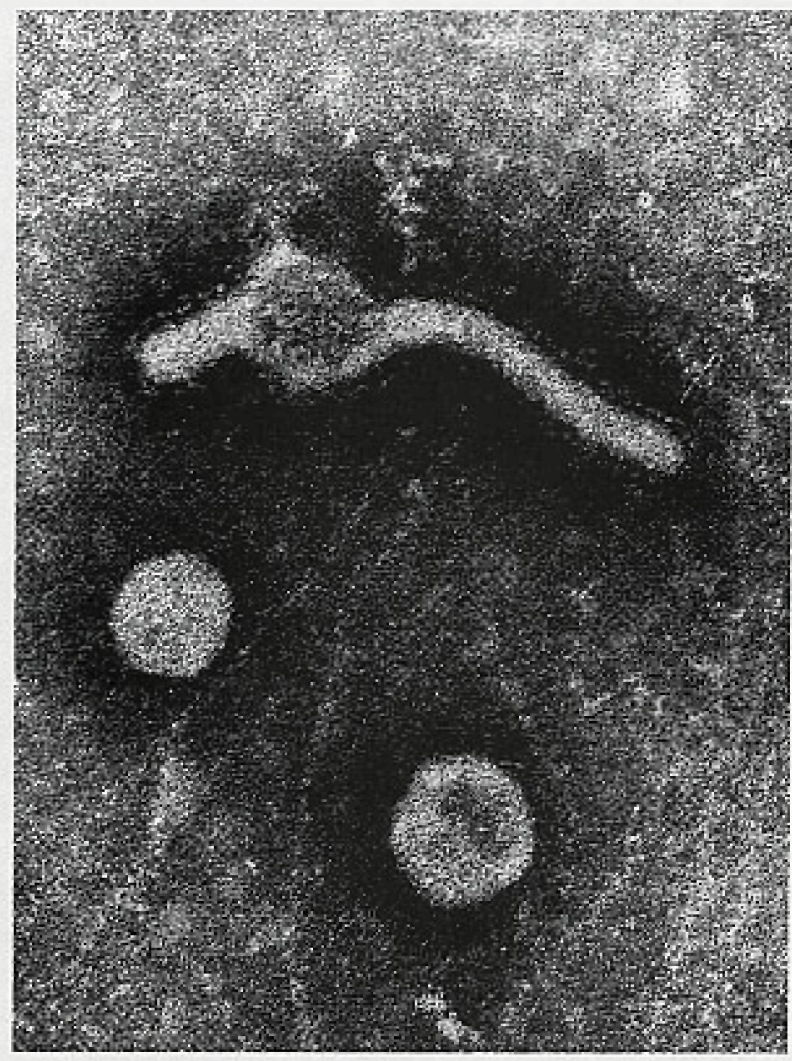

Figure 3-Sendai Virus

\section{EDS Upgrades}

Upgrade your existing EDX system with the world leader in affordable EDX upgrades.

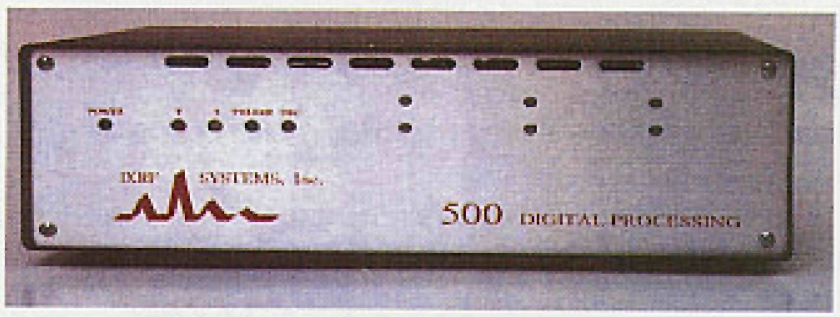

Our new digital pulse processor provides increased throughput and will interface to most EDS detectors.

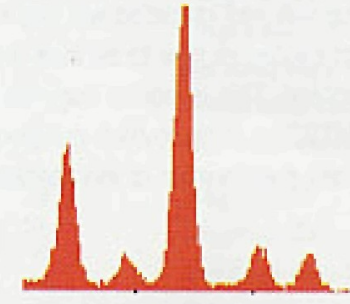

Precise Standardless quantitation for even complex matricies

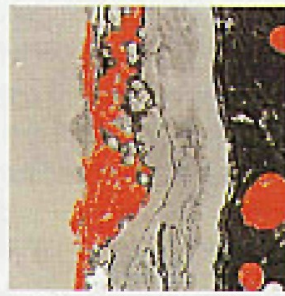

"Active" digital imaging, linescans, and $x$-ray mapping.
Combining digital imaging with our EDS system produces a very simple yet powerful Microanalysis system.

DXRF has established it-self as a "leader" in the Microanalysis industry as most of the major EDS companies convert from analog to digital systems.

Hundredsof systems installed

- Easy to use Windows 95 or NT

- Each system comes complete with Pentium PC

- Installation and training at your site

- New detectors available

- Morphology and Feature analysis

- Automatic Point Analysis

- Quantitative Mapping and Linescans

IXRF Systems, Inc. 15715 Brookford Dr: Houston, TX 77059

Tel:281/286-6485 Fax:281/286/2660 Website: ixrfsystem s.com 